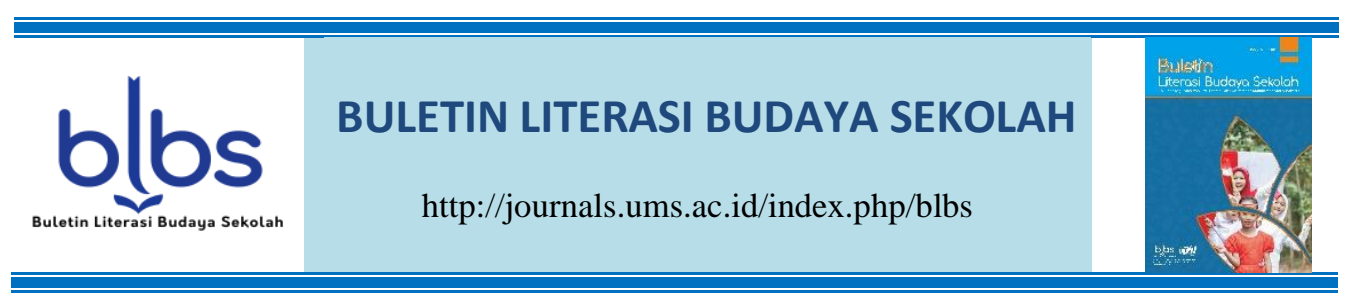

\title{
UPAYA MEMINIMALISASI DISKALKULIA PADA SISWA KELAS 7G DI SMP NEGRI 2 KARTASURA
}

Lia Kusuma Jati ${ }^{1}$, Muhammad Ponco Prasetyo ${ }^{2}$, Nurul Shalihah ${ }^{3}$ \& Titik Asmawati ${ }^{4}$

$1,2,3,4$ Universitas Muhammadiyah Surakarta

Jl. A. Yani Tromol Pos 1 Pabelan Kartasura, Surakarta, Indonesia

Email \& Phone: Titik.Asmawati@ums.ac.id \& +62 85647382407

Submitted: 2020-09-07

Accepted: 2020-09-29

Published: 2020-12-07

\begin{tabular}{ll}
\hline Keywords: & \multicolumn{1}{c}{ Abstract } \\
\hline $\begin{array}{l}\text { dyscalculia, } \\
\text { difficulty }\end{array}$ & This article discusses the existence of disease or dyscalculatic \\
learning, & problems experienced by junior high school students, especially \\
basic concepts & in the $7 G$ grade. This research was conducted at SMP Negeri 2 \\
of & Kartasura. The background of this research is the difficulty of \\
mathematics & students in understanding the basic concepts of mathematics. \\
& Diskalkulia is a form of learning difficulties experienced by \\
& children in learning mathematics. In fact, almost all students \\
& say that mathematics is the most difficult subject. If it's not \\
& difficult that means it's not math. Given the importance of \\
& mathematics in science and technology, it is only natural that \\
& mathematics becomes a compulsory subject that needs to be \\
& mastered and well understood by students in schools. The need \\
& forcurrent and future mathematical applications is not only for \\
& everyday use, but especially in the world of work, and to \\
& support science. The cause of learning difficulties in \\
& mathematics is a common problem that often occurs in \\
& children in schools, with different types and different levels of \\
& difficulty. Problems experienced by students to understand the \\
basic concepts of mathematics are influenced by several & factors including internal factors of students who consider \\
& mathematics difficult, lack of student interest in learning \\
mathematics. Whereas external factors include, the method \\
used by the teacher in delivering material is less interesting so \\
students feel bored when learning takes place.
\end{tabular}

\section{PENDAHULUAN}

Pendidikan merupakan suatu hal yang penting bagi manusia, karena pendidikan bertujuan untuk mendidik dan membangun agar manusia dapat memiliki keterampilan dan kecerdasan. Menurut Undang-Undang No. 20 Tahun 2003 pendidikan adalah usaha sadar dan terencana untuk mewujudkan suasana 
belajar dan proses pembelajaran agar peserta didik secara aktif mengembangkan potensi dirinya untuk memiliki kekuatan spiritual keagamaan, pengendalian diri, kepribadian, kecerdasan, akhlak mulia, serta keterampilan yang diperlukan dirinya, masyarakat, bangsa dan negara. Matematika sebagai salah satu disiplin ilmu yang berhubungan dengan dunia pendidikan yang dapat mengembangkan kemampuan untuk berargumentasi, memberi kontribusi dalam penyelesai masalah sehari-hari. Mengingat pentingnya matematika dalam ilmu pengetahuan dan teknologi, maka sudah sewajarnya matematika menjadi pelajaran wajib yang perlu dikuasai dan dipahami dengan baik oleh siswa di sekolah-sekolah.

Dapat disimpulkan bahwa matematika merupakan ilmu yang memiliki peranan penting bagi kemajuan peradaban bangsa. Pada kenyataannya masih banyak siswa yang duduk di Sekolah Menengah Pertama yang mengalami kesulitan dalam belajar matematika. Kesulitan belajar adalah masalah umum yang banyak terjadi pada anak-anak di sekolah, dengan keberagaman jenis dan tingkat kesulitan yang berbeda-beda. Kondisi ini tentu saja menjadikan persoalan tersendiri dalam pemberian layanan yang sesuai dengan kebutuhan mereka masing-masing. Mengingat adanya variasi jenis dan bentuk kesulitannya yang sangat banyak, maka pelayanan pendidikan dengan pendekatan individual akan sangat sesuai untuk memenuhi kebutuhannya. Kesulitan belajar juga dapat mencakup kesulitan mengerjakan soal matematika. Jadi, pada umumnya anak memiliki kesulitan belajar pada bidang akademis, yaitu membaca, menulis, dan matematika. Kesulitan belajar dalam matematika merupakan hal yang jarang dipahami oleh orang lain. Kesulitan belajar matematika hingga saat ini masih banyak orang tua yang tidak tahu dengan diskalkulia anaknya. Padahal anak yang diskalkulia perlu bimbingan dan motivasi yang baik untuk memperbaiki dirinya.

Anak berkesulitan belajar terbagi dalam tiga kategori yaitu, dislekasia, disgrafia, dan diskalkulia (Yofelia dan Efendi, 2019:36). Dyscalculia berasal dari bahasa Yunani yang memiliki arti ketidakmampuan berhitung. Kata "dys" berarti "ketidakmampuan" sedangkan "calculus" berarti "kerikil", manik, dekak atau kelereng. Karena zaman dahulu menghitung dengan alat bantu kerikil maka dari sinilah istilah diskalkulia berasal (Suzana dan Maulida, 2019:18). Diskalkulia adalah suatu kondisi yang terjadi karena adanya kelemahan pada anak dalam menyelesaikan soal-soal mengenai pembelajaran berhitung seperti, penjumlahan, pengurangan, dan sebagainya (Reafani, Fatmawati, dan Irdamurni, 2017:13). Menurut Putri, Gracia Hutami dalam Arisandi (2011:478) kesulitan belajar atau diskalkulia adalah kesulitan belajar yang menyebabkan anak tidak dapat berhitung, mengalami kesulitan dalam memahami konsep pelajaran matematika. Diskalkulia terjadi ketika seorang anak tidak mampu memahami konsep-konsep hitung matematika atau mengenali simbol-simbol aritmatika (tambah, kurang, bagi, kali, dan akar).

Menurut Suharmini dalam Mutiani dan Suyadi (2020:105) Diskalkulia merupakan ketidakmampuan berhitung yang disebabkan adanya gangguan pada sistem saraf pusat. Sering kali siswa lemah dalam kemampuan persepsi sosial, lemah dalam konsep arah dan waktu, serta gangguan pada memorinya. Siswa mengalami kesulitan dalam membedakan bentuk geometrik, simbol, konsep angka, sulit menghafal penjumlahan, pengurangan, perkalian, dan pembagian secara cepat. Bagi anak yang memiliki masalah diskalkulia, intervensi atau melakukan 
sesuatu untuk merubah suatu kondisi yang dilakukan lebih dini akan membantu anak lebih mudah menghadapi kesulitannya. Pemahaman yang baik tentang konsep matematika di usia dini akan membantu anak lebih mudah memahami konsep matematika di tingkat selanjutnya (Fathimah dan Ishartiwi, 2018:116).

Menurut Subini dalam Karim dkk (2020:275) terdapat dua faktor penyebab seorang siswa kesulitan dalam belajar matematika yaitu: 1) faktor internal pada diri siswa seperti daya ingat, terganggunya alat indra, usia anak, jenis kelamin, kebiasaan belajar tingkat kecerdasan, minat, dan emosi; 2) faktor eksternal pada diri siswa yakni faktor keluarga, sekolah dan lingkungan masyarakat. Kesulitan belajar dari neurobiologis ini ditandai oleh pengenalan kata yang buruk, kesulitaan mengeja dan kemampuan mengelompokkan, meskipun memiliki kemampuan kognitif yang lebih tinggi (Sinaga dan Simarmata, 2020:220). Tidak semua anak yang belum bisa membaca atau berhitung dikategorikan sebagai anak dislesia atau diskalkulia, namun bisa jadi kesulitan mereka dalam belajar membaca ataupun berhitung disebabkan oleh kesulitan membedakan hurup dan angka seperti dijelaskan pada anak penderita dileksia dan diskalkulia (Purnomo dkk, 2017:498). Demikian akibat dari terganggu neurologi, proses psikologis dasar ataupun penyebab lainlah yang mengakibatkan anak mengalami kesulitan saat pembelajaran. Oleh sebab itu, agar anak dalam pembelajaran tidak mengalami kesulitan maka diperlukan perhatian khusus terutama pada keaktifan dan keterlibatanya dalam pembelajaran (Malay dan Armaini, 2020:40).

Santrock (2012: 324) menyatakan bahwa terdapat tiga macam kesulitan belajar pada anak yaitu disleksia, disgrafia, dan diskalkulia. Diskleksia yaitu kategori bagi individuindividu yang memiliki gangguan parah dalam hal membaca dan mengeja. Disgrafia yaitu kesulitan belajar yang mencakup kesulitan dalam hal menulis tangan. Sedangkan diskalkulia yaitu gangguan perkembangan aritmatika, yaitu kesulitan belajar yang terkait dengan perhitungan matematika. Diskalkulia merupakan bentuk kesulitan belajar yang dialami anak dalam belajar matematika. Murtadlo (2013) diskalkulia ialah kesulitan belajar yang menggunakan aspek dasar dari keterampilan aritmatika. Kesulitannya terdapat pada sektor memahami, penerimaan, atau memproduksi informasi yang bersifat kuantitatif dan spasial.

Siswa yang mengalami diskalkulia dapat mengalami permasalahan dalam pemahaman konsep bilangan (angka) sederhana, kurangnya pemahaman dalam persepsi sebuah angka dan mempunyai permasalahan belajar dalam hal perhitungan dan prosedur. Oleh karena itu strategi untuk membantu anak yang mengalami diskalkulia adalah dengan cara memberikan soal-soal secara bertahap dan berkelanjutan yang berpedoman pada teori konstruktivisme. Berdasarkan teori belajar yang dikemukakan bahwa kesulitan belajar anak berupa diskalkulia dapat diatasi dengan caradibimbing dan dibiasakan memcahkan soal-soal matematika. Anak yang sulit belajar aritmatika, sulit untuk dikatakan memiliki masalah diskalkulia. Hal ini dikarenakan pelajaran matematika merupakan pelajaran yang cukup sulit bagi anak.

Diskalkulia pada anak yang belajar matematika hampir sama sekali tidak dikenali. Banyak orang tua yang tidak mempercayai dan tidak mengetahui mengalami kalau anak mereka diskalkulia. Karena para orang tua bahwa kemampuan anak percaya mereka memang seperti itu dan tugas guru-guru di 
sekolah adalah membantu materi anak mereka memahamkan pelajaran matematika.

Penelitian ini bertujuan untuk mengetahui faktor yang menjadi penyebab diskalkulia pada siswa SMP dan bagaimana proses belajar dapat berjalan menyenangkan menggunakan strategi pendekatan guru dengan murid untuk mengatasi diskalkulia.

\section{METODE}

Peneliti dalam meneliti menggunakan Pendekatan Kuantitatif untuk jenis survei yang diadaptasi dari (Creswell, 2009). Penelitian yang dilakukan adalah metode penelitian survei deskriptif, dimana bermaksud untuk mengumpulkan data atau informasi dengan menggunakan sampel. Lokasi penelitian di SMP Negeri 2 Kartasura terletak di JI. A. Yani Tromol Pos 1 Pabelan Kartasura Surakarta Jawa Tengah. Waktu penelitian dilakukan pada : Jumat, 7 Februari 2020, pukul $09.45 \mathrm{~s} / \mathrm{d}$ 10.25 WIB. Jumlah partisipan peserta adalah kelas $7 \mathrm{G}$ yang berjumlah 30 siswa di SMP Negeri 2 Kartasura. Instrumen penelitiannya adalah berupa soal tes tulis mengenai permasalahan materi matematika dasar. Teknik pengumpulan data menggunakan teknik observasi, kuisioner, dan wawancara. Analisis data menggunakan metode penyimpulan jawaban dari kuisioner yang berhubungan dengan soal matematika dasar yang diberikan.

\section{HASIL DAN PEMBAHASAN}

Dari kuisioner yang diberikan terhadap siswa kelas 7G SMP Negeri 2 Kartasura didapatkan hasil:

1. Ketika siswa diberi pertanyaan mengenai kesulitan dalam mengerjakan soal yang diberikan, $70 \%$ dari mereka menganggap bahwa soal yang diberikan sulit dengan alasan antara lain tidak mengetahui cara penyelesaiannya, kurangnya kesadaran siswa untuk mengulang kembali materi yang telah diberikan, dan siswa merasa tidak fokus dalam menyelesaikan soal karena merasa tertekan dengan waktu yang telah diberikan. 30\% siswa merasa tidak kesulitan karena materi pada soal pernah diberikan atau dipelajari, dan siswa sudah paham dengan materi yang diberikan.

2. Waktu yang diberikan selama 15 menit untuk mengerjakan soal, $66 \%$ siswa mengatakan waktu yang diberikan tidak cukup, sehingga mengakibatkan siswa tidak dapat mengerjakan soal dengan maksimal dan hanya $33 \%$ siswa yang merasa waktu 15 menit cukup untuk mengerjakan soal yang diberikan.

3. Banyak siswa yang hanya mengerjakan latihan soal matematika ketika mereka diberi tugas oleh guru, tidak lebih dari $16 \%$ siswa saja yang mengerjakan latihan soal matematika diluar jam pelajaran dengan jumlah kurang dari 10 soal, sehingga kesadaran siswa untuk mengerjakan latihan soal masih kurang.

4. Tidak banyak siswa yang mengatakan matematika menyenangkan, hanya $16 \%$ siswa menganggap matematika menyenangkan. $83 \%$ siswa mengatakan matematika tidak menyenangkan dengan alasan kesulitan menghafalkan rumus dan cara guru menyampaikan materi tidak 
menyenangkan. Tetapi ada siswa yang menilai matematika menyenangkan tergantung dari materi yang sedang dipelajari.

5. Saat siswa diberi pertanyaan tentang faktor apa saja yang membuat mereka sulit dalam memahami pelajaran matematika, dari jawaban mereka dapat digolongkan menjadi 3 faktor yaitu faktor eksternal yang berkaitan dari cara guru menyampaikan materi. Siswa menganggap metode guru dalam menyampaikan materi kurang menarik atau membosankan. Sedangkan faktor internal, siswa sudah menganggap bahwa matematika adalah pelajaran yang sulit bahkan menakutkan sehingga mereka cenderung membatasi diri untuk berusaha berkembang. Faktor soal dan rumus, beberapa siswa merasa pengembangan soal dalam matematika terlalu sulit dan mereka masih belum bisa menggunkan rumus yang seharusnya.

Ada beberapa masalah yang dialami siswa dalam menghitung, seperti :

1. Siswa masih belum mampu menyelesaikan soal operasi hitung seperti 5 $12 \times 2-(-15)$, siswa cenderung tidak memperhatikan tanda tersebut.

2. Siswa masih belum mampu menyelesaikan soal tentang mencari variabel $X$ dalam bentuk yang telah dikembangkan $4-x=5$, siswa masih belum bisa menerapkan aturan pindah ruas.

3. Sebagian besar siswa sudah bisa mengkonversi satuan berat, dan waktu. Tetapi ada beberapa yang belum bisa mengkonversi waktu dari detik ke jam.

4. Dari soal penjumlahan pecahan cara siswa menyelesaikan soal tersebut menunjukkan siswa telah menguasai konsep operasi bilangan pecahan.

5. Siswa masih belum paham tentang konsep operasi akar, mereka cenderung menganggap tanda akar ( $\mathrm{V} 48$ ) sama dengan membagi 2 .

6. Siswa kurang memahami tanda persen sehingga mereka salah dalam menyelesaikan soal yang berkaitan dengan tanda persen (\%).

Dari survei yang telah dilakukan dapat diketahui ada beberapa siswa yang mengalami diskalkulia. Dari data yang diperoleh siswa belum memahami konsep dasar aritmatika untuk menyelesaikan permasalahan matematika yang digolong mudah untuk siswa kelas 7. Beberapa cara yang dapat digunakan untuk meminimalisasi diskalkulia dengan cara pemberian motivasi terhadap siswa, mengulang kembali konsep yang pernah diajarkan, mengubah anggapan siswa mengenai matematika yang sulit menjadi matematika yang menyenangkan, menggunakan metode pembelajaran yang menyenangkan sehingga dapat menarik minat siswa untuk belajar matematika.

\section{SIMPULAN}

Dari observasi yang dilakukan didapatkan suatu permasalahan pada siswa kelas $7 \mathrm{G}$ mengenai pemahaman konsep dasar matematika atau dapat disebut diskalkulia yang disebabkan oleh beberapa faktor antara lain faktor internal dari siswa yang menganggap matematka sulit, kurangnya minat siswa terhadap pembelajaran matematika. Sedangkan faktor eksternal meliputi, metode yang digunakan guru dalam menyampaikan materi kurang menarik sehingga siswa merasa bosan saat pembelajaran berlagsung. Solusi yang dapat dilakukan adalah dengan mengubah anggapan siswa mengenai matematika yang sulit menjadi 
matematika yang menyenangkan, pemberian motivasi terhadap siswa, mengulang kembali konsep yang pernah diajarkan, mengubah anggapan siswa mengenai matematika yang sulit menjadi matematika yang menyenangkan, menggunakan metode pembelajaran yang menyenangkan sehingga dapat menarik minat siswa untuk belajar matematika.

Guru di sekolah perlu membangun kerja sama dengan anak untuk membsntu anak meminimalisir diskalkulia yang mereka alami. Anak yang mengalami diskalkulia, biasanya lebih banyak diam diri dari teman-temannya karena merasa dirinya tidak mampu. Anak yang mengalami diskalkulia juga biasanya jarang diajak bermain dengan temannya karena temantemannya merasa disusahkan. Jika pun diajak bermain, maka anak tersebut biasanya hanya mengikuti perintah dari teman yang mengajaknya bermain. Kehidupan anak yang mengalami diskalkulia memperlihatkan bahwa mereka anak yang butuh untuk dipahami perihal kegiatannya, tetapi tidak jarang orang mengabaikan ini. Karena anak yang mengalami diskalkulia dapat menjadi baik, jika dituntun dan dimbimbing dalam belajar.

\section{DAFTAR PUSTAKA}

Arisandi, Elisa. (2011). Meningkatkan Kemampuan Operasi Perkalian untuk Anak Diskalkulia Melalui Metode Garismatika. E-JUPHEKhu, 3(3), 478-488.

Fathimah, Nusuki Syari'ati., \& Ishartiwi. (2018). Pengembangan Multimedia Permainan Interaktif Pembelajaran Berhitung Bagi Anak Diskalkulia Usia Prasekolah. Jurnal Inovasi Teknologi Pendidikan, 5(2), 115-128.

Karim, Abdul., Purnama, Indah Mayang., \& Wiratomo, Yogi. (2020). Rancang Bangun Bahan Ajar Siswa Diskalkulia Sekolah Dasar. Jurnal Kajian Pendidikan Matematika, 5(2), 273-288.

Malay, Dailami., \& Armaini. (2020). Meningkatkan Kemampuan Mengenal Bentuk Bangun Datar Melalui Permainan Engklek Pada Anak Diskalkulia. Indonesian Journal of Instructional Technology, 1(1), 39-45.

Mutiani, Ria., \& Suyadi, Suyadi. (2020). Diagnosa Diskalkulia Generasi Alpha: Masalah dan Perkembangannya. Jurnal Edumaspul, 4(1), 104-112.

Purnomo, Agus dkk. (2017). Pengembangan Game untuk Terapi Membaca Bagi Anak Disleksia dan Diskalkulia. Jurnal Simetris, 8(2), 497-506.

Reafani, Sevira., Fatmawati, Irdamurni. (2017). Media Puzzle Kartu Angka Meningkatkan Kemampuan Operasi Pengurangan bagi Anak Diskalkulia. Jurnal Pendidikan Kebutuhan Khusus, 1(1), 13-18.

Sinaga, Reflina., \& Simarmata, Ester Julianda. (2020). Media Gambar Terhadap Diskalkulia di Sekolah Dasar. Jurnal Tunas Bangsa, 7(2), 219-234. 
Suzana, Yenny., \& Maulida, Iyana. (2019). Mengatasi Dampak Negatif Diskalkulia Dalam Menyelesaikan Masalah Matematika. Logaritma: Jurnal IImu-ilmu Pendidikan dan Sains, 7(1), 15-26.

Yofelia, Nadya., \& Efendi, Jon. (2019). Meningkatkan Hasil Belajar Operasi Pengurangan Deret Kebawah Anak Diskalkulia Menggunakan Gelas Bilangan. Ranah Research, 2(1), 35-42. 